2018

\title{
Development of a Light-Commercial Compressor Load Stand to Measure Compressor Performance using Low-GWP Refrigerants
}

Drew Schmidt

Oklahoma State University, United States of America, drew.schmidt@okstate.edu

Jake Singleton

Oklahoma State University, United States of America, jake.singleton@okstate.edu

Craig Bradshaw

Oklahoma State University, United States of America, craig.bradshaw@okstate.edu

Follow this and additional works at: https://docs.lib.purdue.edu/icec

Schmidt, Drew; Singleton, Jake; and Bradshaw, Craig, "Development of a Light-Commercial Compressor Load Stand to Measure Compressor Performance using Low-GWP Refrigerants" (2018). International Compressor Engineering Conference. Paper 2614. https://docs.lib.purdue.edu/icec/2614

This document has been made available through Purdue e-Pubs, a service of the Purdue University Libraries. Please contact epubs@purdue.edu for additional information.

Complete proceedings may be acquired in print and on CD-ROM directly from the Ray W. Herrick Laboratories at https://engineering.purdue.edu/ Herrick/Events/orderlit.html 


\title{
Development of a Light-Commercial Compressor Load Stand to Measure Compressor Performance using Low-GWP Refrigerants
}

\author{
Drew SCHMIDT ${ }^{1 *}$, Jake SINGLETON ${ }^{2}$, Craig R. BRADSHAW ${ }^{3}$ \\ Building \& Environmental Thermal Systems, Oklahoma State University, \\ Stillwater, OK, USA \\ Email: 1drew.schmidt@okstate.edu \\ Email: ${ }^{j}$ jake.singleton@okstate.edu \\ Email: ${ }^{3}$ craig.bradshaw@okstate.edu \\ * Corresponding Author
}

\begin{abstract}
Popular hydrofluorocarbon refrigerants such as R134a and R410A are in the process of being phased out due to the high Global Warming Potential (GWP) of these fluids. A large variety of low-GWP refrigerants are being considered as replacements including R1234yf, R1234ze(E), R1234ze(D), R32, and blends of these with traditional refrigerants. As a result of high efficiency standards for HVAC\&R equipment, the choice of refrigerant has a large impact on the design of a compressor to maximize its efficiency. Therefore, changing the most common refrigerants will require significant design changes to compressors and test environments that support re-design activities such as a hot-gas bypass compressor load stand. The hot-gas bypass style is a common system design to test compressors and is used for its many benefits, including rapid movement between testing conditions and low operational cost. A thermodynamic model of a hot-gas bypass cycle has been developed in Engineering Equation Solver (EES). Outputs from this model were used to select the components and piping sizes in combination with ASHRAE guidelines. The design capacity for the load stand is a range of 10-80 tons (35-281 kW), compressor capacity. The large range in capacities desired created many design challenges to overcome including maintaining proper oil circulation and refrigerant velocity. Once constructed, the compressor load stand will be capable of testing the performance of different compressors over a range of operating conditions. It will also have independent control over oil circulation/injection rate as well as a dedicated economizer circuit. These capabilities can then be used to optimize a wide spectrum of compressor types on low-GWP refrigerants. Ultimately, the load stand will serve as a new addition to the thermal systems research infrastructure at Oklahoma State University. This will allow for the continuation of research into new compressor technologies, as well as, for improvements in compressor efficiency in existing technologies.
\end{abstract}

\section{INTRODUCTION}

Recently, there has been a push to improve the efficiencies and reduce the environmental impact of HVAC\&R systems. In 2016, 111 quadrillion BTUs of energy were used by the United States (US Energy Flow, 2016), 40 percent of this being consumed by commercial and residential HVAC\&R systems with $18 \%$ used by the compressors of these systems, on average. The high energy consumption of compressors creates importance to improve the efficiencies of compressor technology to reduce their environmental footprint.

One way to reduce the environmental impact of HVAC\&R systems is to reduce the use of HFC refrigerants and to switch to low-Global Warming Potential (GWP) refrigerants. In fact, the Kigali Amendment to the Montreal Protocol requires countries to reduce HFC use by 85 percent between 2019 and 2036. It is predicted by Dr. Guus Velders, that these changes alone will mitigate an increase in global surface temperature of $0.5^{\circ} \mathrm{C}$ (Doniger, 2016). To realize this reduction in environmental impact, it is necessary to begin the switch to low-GWP refrigerants immediately. This requires design, development, and modeling activities for various compressor technologies, supported by experimental data. Therefore, it is essential to develop testing environments to determine how compressors will perform using new refrigerants. Since there is a wide range of low-GWP refrigerants that could be used, data will need to be collected to measure compressor efficiency operating with each refrigerant. Currently, a hot-gas bypass compressor load stand is 


\section{5, Page 2}

being constructed at Oklahoma State University for the purpose of testing a wide variety of compressors with a wide variety of refrigerants, including low-GWP, to characterize compressors and support design, development, and modeling activities. The load stand operates using the principle of hot-gas bypass operation, and includes features such as economization and independent lubricant management.

The hot-gas bypass configuration offers several advantages that are not seen with other types of compressor test setups such as a calorimeter. Sathe et al. (2008) describes many of these advantages. With fewer components than a calorimeter, a hot-gas bypass stand is easier to construct and operate. It is also able to rapidly move between test conditions and offer a more stable operating condition due to the bypass and liquid expansion valve control scheme. An evaporator is not needed and smaller condensers can be used due to most of the refrigerant flow being bypassed.

Experiments using hot-gas bypass compressor load stands have been done for several applications to develop new compressor technologies. Bradshaw et al. (2011) designed a load stand to test the performance of a custom-designed miniature linear compressor. They were able to control the temperature and pressure of the inlet and the pressure at discharge by controlling flowrates through the system using expansion valves. Similarly, the model of the novel rotating spool compressor developed by Bradshaw and Groll (2013) was validated using data from a hot-gas bypass style load stand testing a 5-ton $(18 \mathrm{~kW}), \mathrm{R} 410 \mathrm{~A}$, spool compressor prototype with data presented in Orosz et al. (2014). As a follow-on study, a 40-ton (141 kW), R134a, spool compressor prototype was developed on a separate hot-gas bypass compressor load stand with data presented in Orosz et al. (2016). This experience with hot-gas bypass load stand design and operation to support compressor development lead to a series of best practices of hot-gas bypass load stand environments present by Bradshaw (2014) that this work has followed.

Additional considerations have been made to compressor load stands to include novel cycle modifications such as liquid, vapor, and oil injection. Gu and Mathison (2014) developed a load stand to test compressors with two vapor injection ports and therefore two pressures between the suction and discharge. They determined that lowering the condensing temperature would result in a lower quality of injection. Bell (2011) presented data from an oil injected scroll compressor using a modified hot-gas bypass load stand configuration. This study presented the potential improvements to compressor efficiency as a result of oil injection. To enable the ability to test these advanced cycle modifications the load stand developed in this work is being constructed to be able to test compressors installed in these simulated cycles.

\section{LOAD STAND DESIGN}

The design envelope of the load stand is a max of 80 tons $(281 \mathrm{~kW})$ cooling capacity at $55^{\circ} \mathrm{C}$ condensing temperature with the working fluid R134a, the minimum capacity being 10 tons $(35 \mathrm{~kW})$ at the same condensing temperature. The design objective being to have the ability to cover a capacity range suitable for light-commercial compressors of varying sizes and types, specifically small screw compressors and large scroll compressors. Along with this wide light-commercial capacity spectrum, the hot-gas bypass system includes a dedicated economizer circuit allowing for liquid or vapor refrigerant injection, as well as, independent control over oil circulation and injection. The schematic in Figure 1 shows the system layout consisting of all major components and instrumentation. Highlighted in Figure 1, the load stand consists of three distinct loops, one for each feature including the main, economizer, and oil loops.

The main loop controls the simulated system operating conditions exposed to the compressor. The operation of this loop starts at the desired suction test condition (1) where the refrigerant enters the compressor at a controlled intake temperature and pressure, and is then discharged at a controlled sub-critical pressure. The refrigerant flow then enters a coalescent oil separator before passing through a Coriolis mass flow meter. Exiting the mass flow meter, the refrigerant separates into two distinct paths (2). A majority of the flow is bypassed through a set of electronic gas expansion valves back to suction pressure (3). The remaining flow condenses through two parallel water cooled brazed plate heat exchangers, fed into a liquid receiver, subcooled with another brazed plate heat exchanger (4), and then finally expanded back to suction pressure with a set of liquid electronic expansion valves (5). The bypassed hot gas mixes with the expanded liquid, passes through another Coriolis mass flow meter, and creates the desired suction test condition (1). The two main parameters (temperature and pressure) setting the suction condition are achieved through manipulation of the liquid and bypassed gas expansion valves. The amount of liquid allowed to expand sets the suction superheat, while the amount of discharged gas allowed to bypass sets the suction pressure. The control of cooling water through the condensers and sub-cooler allows independent control over the compressor discharge pressure. 
The dedicated economizer loop follows a similar working principle as the main loop of the load stand. A portion of the subcooled liquid flow (4) is separated from the main loop and passes through another Coriolis mass flow meter before expanding to an intermediate pressure. A portion of the discharge gas (2) is also separated from the main loop, passed through a Coriolis mass flow meter, and expanded to an intermediate pressure. The separated flows mix (6) to create the desired injection condition. Again, manipulation of the expansion valves will allow for injection state control, permitting either liquid or vapor injection.

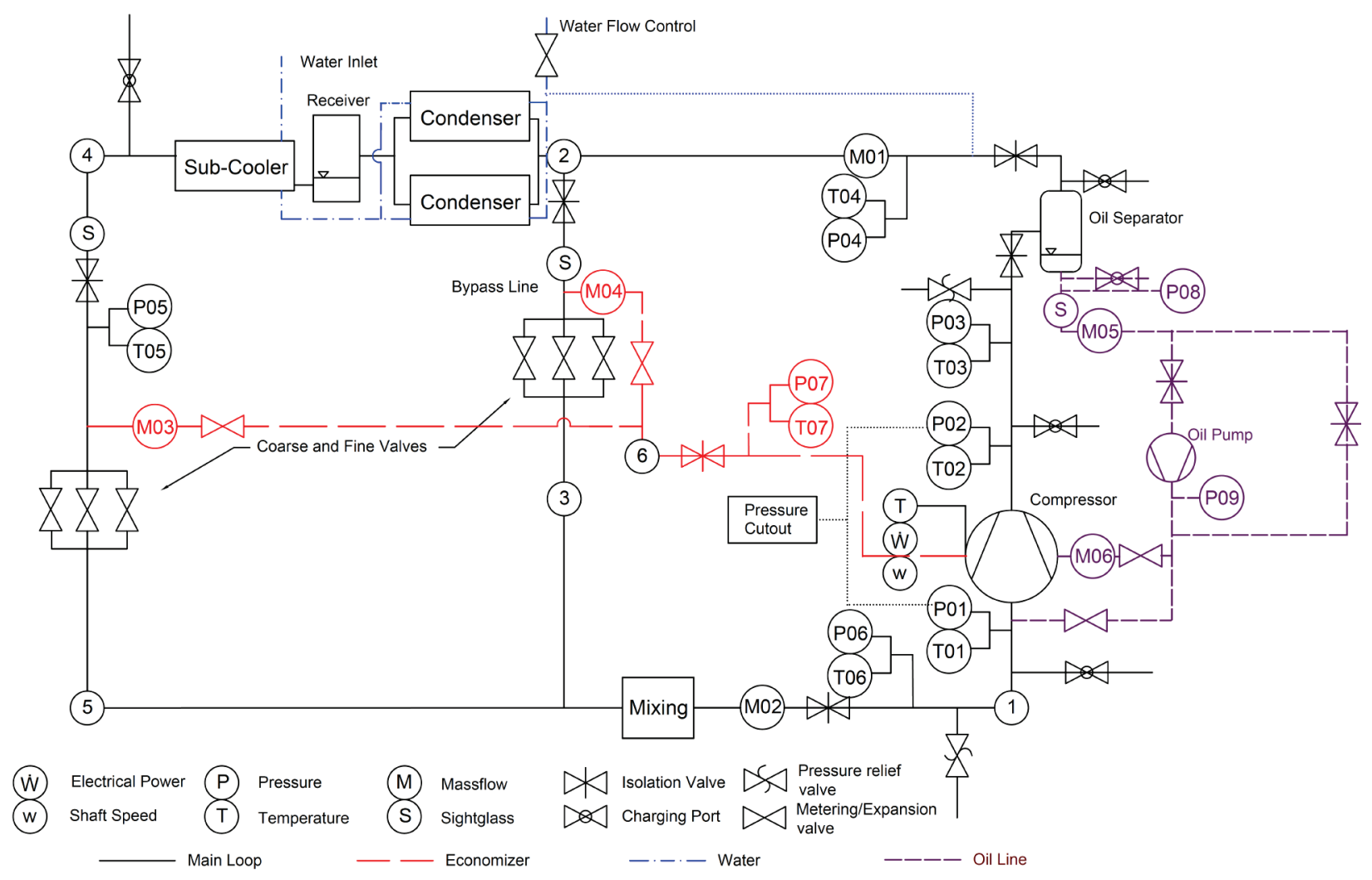

Figure 1: Load Stand Schematic

The oil loop consists of two circuits that return oil separated from the discharge line back to the compressor. One circuit feeds the oil back into the suction line near the compressor, while the second circuit injects the oil into the compressor at an intermediate pressure. Either circuit is designed to operate independently, but may operate together with the second circuit, or not at all depending on the configuration of the isolation ball valves. Two Coriolis mass flow meters, one on each circuit, ensures that the mass flow rates are measured with any configuration running. Metering valves installed on each circuit throttle the oil to the intermediate pressure, as well as, regulate the mass flow ratio between circuits. In the case of a high-pressure shell compressor, an oil pump is used to create the oil flow, with a Variable Frequency Drive (VFD) hooked up to the oil pump motor to regulate oil flow.

\subsection{Instrumentation and Safety}

The instrumentation consists of gage pressure transducers and T-type thermocouples to determine each of the state points discussed above. Critical refrigerant measurements, such as those near the compressor, will use higher accuracy pressure transducers and platinum RTD's for reduced measurement uncertainty. Mass flow measurements are obtained with Coriolis mass flow meters located on the suction and discharge lines, economizer gas and liquid lines, and on the oil main and injection lines. The discharge line meter (M01) is the primary meter for efficiency calculations. Surface mount thermocouples will measure compressor shell temperature, while an accelerometer will measure the compressor shaft speed. Compressor speed modulation is handled through a 150 horsepower $(112 \mathrm{~kW}) \mathrm{VFD}$, with a watt transducer measuring the power supplied to the compressor from the VFD. Instrumentation accuracies can be seen in Table 1 below. For compliance with ASHRAE 23.1, the mass flow measurements are redundant (suction and 
discharge). Additionally, critical pressure and temperature measurements are redundant to ensure rapid diagnosis of sensor failure or calibration problems.

Table 1: Instrumentation Specifications

\begin{tabular}{|c|c|c|c|}
\hline Sensor Type & Model Number & Measure Range & Accuracy \\
\hline Pressure Transducer & $\begin{array}{c}\text { Setra } \\
\text { 2061-10CP-G-2M-11-H1-8-GN }\end{array}$ & $0-1,000$ psi & $\pm 0.13 \% \mathrm{FS}^{1}$ \\
\hline Thermocouple T-type & $\begin{array}{c}\text { Pyromation } \\
\text { T28U-XXX-12B-6MC }\end{array}$ & $0-370^{\circ} \mathrm{C}$ & $\pm 1{ }^{\circ} \mathrm{C}$ or $0.75 \%$ \\
\hline $\begin{array}{l}\text { Pressure Transducer } \\
\text { P01,P02 }\end{array}$ & $\begin{array}{c}\text { Setra } \\
\text { ASM1-750P-G-2M-11-B3-A-00 }\end{array}$ & $0-750 \mathrm{psi}$ & $\pm 0.05 \% \mathrm{FS}^{1}$ \\
\hline Surface Thermocouple & $\begin{array}{c}\text { Omega } \\
\text { SA1XL-T-72-SRTC }\end{array}$ & $-60-175^{\circ} \mathrm{C}$ & $\pm\left(0.004 \cdot \mathrm{t}^{1}\right)^{\circ} \mathrm{C}$ \\
\hline $\begin{array}{l}\text { Platinum RTD } \\
\text { T01, T02 }\end{array}$ & $\begin{array}{c}\text { Pyromation } \\
\text { RAF185L384Z-017-8B15-15- } \\
\text { T3006-4,MC,(Z521) } \\
\end{array}$ & $-30-300{ }^{\circ} \mathrm{C}$ & $\pm\left(0.1+0.0017 \cdot \bullet^{1}\right){ }^{\circ} \mathrm{C}$ \\
\hline Accelerometer & $\begin{array}{c}\text { Omega } \\
\text { ACC101 } \\
\end{array}$ & $3 \mathrm{~Hz}-5 \mathrm{kHz}$ & $\pm 0.022 \%^{2}$ \\
\hline Watt transducer & $\begin{array}{c}\text { Ohio Semitronics } \\
\text { P-147E } \\
\end{array}$ & $0-160,000 \mathrm{~W}$ & $\pm 1 \% \mathrm{FS}^{1}$ \\
\hline $\begin{array}{l}\text { Discharge Mass Flow meter } \\
\text { M01 }\end{array}$ & $\begin{array}{c}\text { Micromotion } \\
\text { CMF200M419N2BAEZZZ }\end{array}$ & $0-10,000 \mathrm{~kg} / \mathrm{h}$ & $\begin{array}{l} \pm 0.1 \% \text { for mass flow } \\
\pm 0.5 \mathrm{~kg} / \mathrm{m}^{3} \text { for density }\end{array}$ \\
\hline $\begin{array}{l}\text { Suction Mass Flow meter } \\
\text { M02 }\end{array}$ & $\begin{array}{c}\text { Micromotion } \\
\text { F200SA37C2BAEZZZZ }\end{array}$ & $0-18,137 \mathrm{~kg} / \mathrm{h}$ & $\begin{array}{l} \pm 0.2 \% \text { for mass flow } \\
\pm 0.2 \mathrm{~kg} / \mathrm{m}^{3} \text { for density }\end{array}$ \\
\hline $\begin{array}{c}\text { Economizer Liquid meter } \\
\text { M03 }\end{array}$ & $\begin{array}{c}\text { Micromotion } \\
\text { CMFS015M314N2BAECZZTG }\end{array}$ & $0-330 \mathrm{~kg} / \mathrm{h}$ & $\begin{array}{c} \pm 0.1 \% \text { for mass flow } \\
\pm 0.2 \mathrm{~kg} / \mathrm{m}^{3} \text { for density }\end{array}$ \\
\hline $\begin{array}{c}\text { Economizer Bypass meter } \\
\text { M04 }\end{array}$ & $\begin{array}{c}\text { Micromotion } \\
\text { CMFS075M329N2BAEKZZTG }\end{array}$ & $0-14,000 \mathrm{~kg} / \mathrm{h}$ & $\begin{array}{l} \pm 0.1 \% \text { for mass flow } \\
\pm 0.5 \mathrm{~kg} / \mathrm{m}^{3} \text { for density }\end{array}$ \\
\hline $\begin{array}{c}\text { Oil Mass Flow meters } \\
\text { M05, M06 }\end{array}$ & $\begin{array}{c}\text { Micromotion } \\
\text { CMF025M319NRAAEZZZ }\end{array}$ & $0-2,180 \mathrm{~kg} / \mathrm{h}$ & $\begin{array}{c} \pm 0.1 \% \text { for mass flow } \\
\pm 0.2 \mathrm{~kg} / \mathrm{m}^{3} \text { for density }\end{array}$ \\
\hline
\end{tabular}

The load stand will have a safety circuit consisting of an emergency stop button, high pressure cutoff, low pressure cutoff, and proximity sensors ensuring the suction and discharge lines are open. These normally closed safety features will break the circuit providing power to the compressor and oil pump motor VFDs, thus shutting the load stand down.

\subsection{Uncertainty Analysis}

One of the primary objectives of the load stand is to measure compressor efficiency at a range of simulated operating conditions. Consequently, the volumetric efficiency and the overall isentropic efficiency will be calculated for each test done on the load stand. The overall isentropic efficiency is the ratio of work done in an isentropic process to the work done by the compressor in the actual process, as shown by,

$$
\eta_{i s}=\frac{\dot{m}\left(h_{2, s}-h_{1}\right)}{\dot{W}}
$$

The volumetric efficiency is the ratio of refrigerant mass flow to the theoretical maximum mass flow rate; it is given by,

$$
\eta_{v o l}=\frac{\dot{m}}{\rho v_{d} \omega}
$$

\footnotetext{
${ }^{1} \mathrm{FS}$ - Full Scale ; $\mathrm{t}$ - Temperature

${ }^{2}$ Estimated by calculating the uncertainty of frequency measurement using NI CompactRio with NI 9230 accelerometer card.
} 
The volumetric efficiency depends on the discharge mass flow meter for density and mass flow readings and the accelerometer for compressor rotational speed readings.

These calculations also rely on the enthalpies of refrigerant entering and exiting the compressor, which is a function of temperature and pressure. This is the rationale behind using the more accurate pressure transducers (Setra ASM) and temperature sensors (Platinum RTD) for this data collection. The mass flow rate and power output also contribute to the calculation, so the discharge mass flow meter and the watt transducer will be used for this reading, which will contribute to the uncertainty.

Using the absolute accuracies of the sensors in Table 1, an uncertainty calculation was performed for an R134a cycle. The approach that was used to calculate the uncertainties of each primary efficiency calculation is a propagation of error approach expressed generally as,

$$
u_{R}= \pm\left[\left(\frac{x_{1}}{R} \frac{\partial R}{\partial x_{1}} u_{1}\right)^{2}+\left(\frac{x_{2}}{R} \frac{\partial R}{\partial x_{2}} u_{2}\right)^{2}+\cdots+\left(\frac{x_{n}}{R} \frac{\partial R}{\partial x_{n}} u_{n}\right)^{2}\right]^{\frac{1}{2}}
$$

This approach uses the relative uncertainties of each sensor to determine how they propagate the error and affect the overall uncertainty. The overall isentropic efficiency and the volumetric efficiency were found to have relative uncertainties of $\pm 1.0 \%$ and $\pm 3.07 \%$, respectively.

\subsection{Final Physical Layout}

A 3-D CAD model of the load stand aided in the design process, offering visualization of critical design aspects such as component placement and pipe design. Figure 2 shows an isometric view of the final load stand design, with the highlighted major components listed in Table 2 . The heat exchangers and liquid receiver are vertically arranged so that liquid refrigerant collects in appropriate locations. This requires that the condensers be above the liquid receiver, which is above the subcooler. A similar component height arrangement is required for the oil separator and oil pump. The oil pump sits below the oil separator to minimize vapor entering the pump. Label 4 highlights the three main loop circuits discussed in greater detail later. Double risers designed using the 2010 ASHRAE Refrigeration Handbook are installed on the discharge and economizer lines to ensure proper oil migration in lieu of separate circuits.

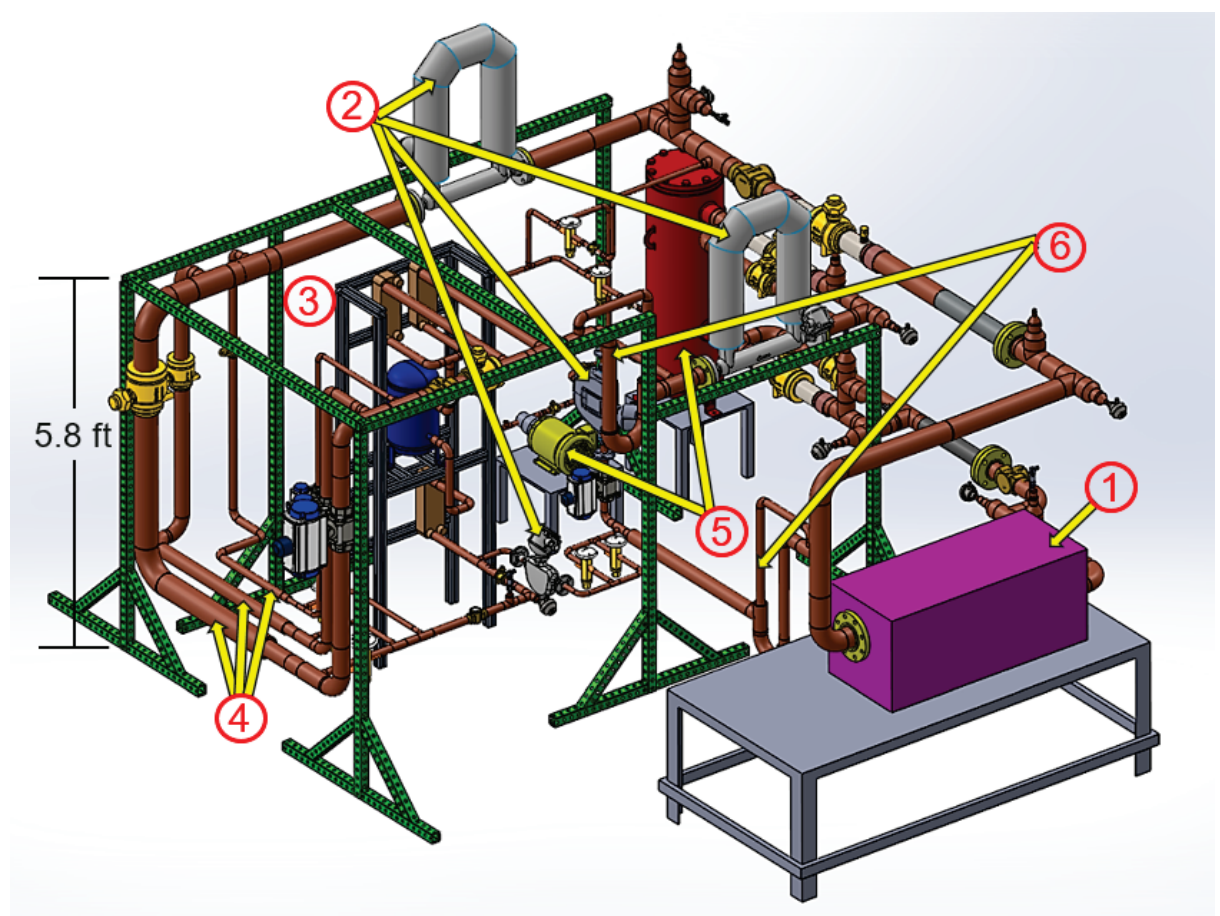

Figure 2: Isometric view of final load stand design 
Table 2: Component List

\begin{tabular}{|c|c|}
\hline Label & Major Component \\
\hline 1 & Compressor \\
\hline 2 & Mass Flow Meters \\
\hline 3 & Heat Exchangers and Liquid Receiver \\
\hline 4 & Main Loop Circuits \\
\hline 5 & Oil Separator and Oil Pump \\
\hline 6 & Double Risers \\
\hline
\end{tabular}

\section{LOAD STAND MODEL}

A thermodynamic model of a hot-gas bypass system, including economization, was developed in Engineering Equation Solver (EES) to represent the operating principles of the load stand. Its purpose is to estimate the load stand system limitations, such as maximum head pressure, and to estimate important conditions, such as mass flow rates, that are needed when selecting and sizing components. This model makes typical assumptions to calculate every thermodynamic state point in the cycle. This includes the compressor being modeled with a fixed isentropic efficiency. All expansion valves are assumed isenthalpic, mixing is assumed adiabatic, and heat exchangers are assumed isobaric. Figure 3 shows the pressure-enthalpy diagram for the load stand predicted by the thermodynamic model. Mass and energy balances, neglecting kinetic and potential energy, were used to calculate the ratio of flow split through the compressor bypass relative to the liquid line for both the main (equation 4) and economizing (equation 5) loops.

$$
\begin{gathered}
\frac{\dot{m}_{10}}{\dot{m}_{6}}=\frac{h_{6}-h_{1}}{h_{1}-h_{10}} \\
\frac{\dot{m}_{7}}{\dot{m}_{8}}=\frac{h_{8}-h_{9}}{h_{9}-h_{7}}
\end{gathered}
$$

To reflect the design conditions previously described (10-80 tons $(35-281 \mathrm{~kW})$ on $\mathrm{R} 134 \mathrm{a}$ with $55^{\circ} \mathrm{C}$ condensing), a parametric study conducted using a normal air side condensing temperature range of $25-60^{\circ} \mathrm{C}$ was performed to explore the various output parameters from the model including the maximum compressor displacement possible to test at $3550 \mathrm{rpm}$. It was found that the max compressor volume displacement corresponding with the aforementioned 80 -ton $(281 \mathrm{~kW})$ objective was $2200 \mathrm{~cm}^{3} / \mathrm{rev}$. Figure 4 shows the plot for the parametric study. Holding parameters such as superheat, subcooling, evaporating temperature, and compressor speed constant, the simulated cooling capacity was found for varying condensing temperatures and volume displacements.

The model takes in various inputs from the user, and outputs the main cycle state points, as well as, various cycle parameters. The inputs are refrigerant type, amount of subcooling and superheat, assumed isentropic compressor efficiency, assumed volumetric efficiency, evaporating temperature, condensing temperature, compressor volumetric displacement, and compressor speed. With these inputs, the model is able to output five main refrigerant state points throughout the load stand. These state points coincide with the suction condition, discharge condition, condensed liquid, expanded liquid, and expanded hot gas. The parameters that it calculates are volume flow rate, mass flow rate, heat rejection, compressor power, and cooling capacity. If the economizer is involved, then some extra inputs include the percent of total compressor volume used for economizing, and the injection temperature. Five more state points are required for the economizing loop, all at the intermediate injection pressure. 


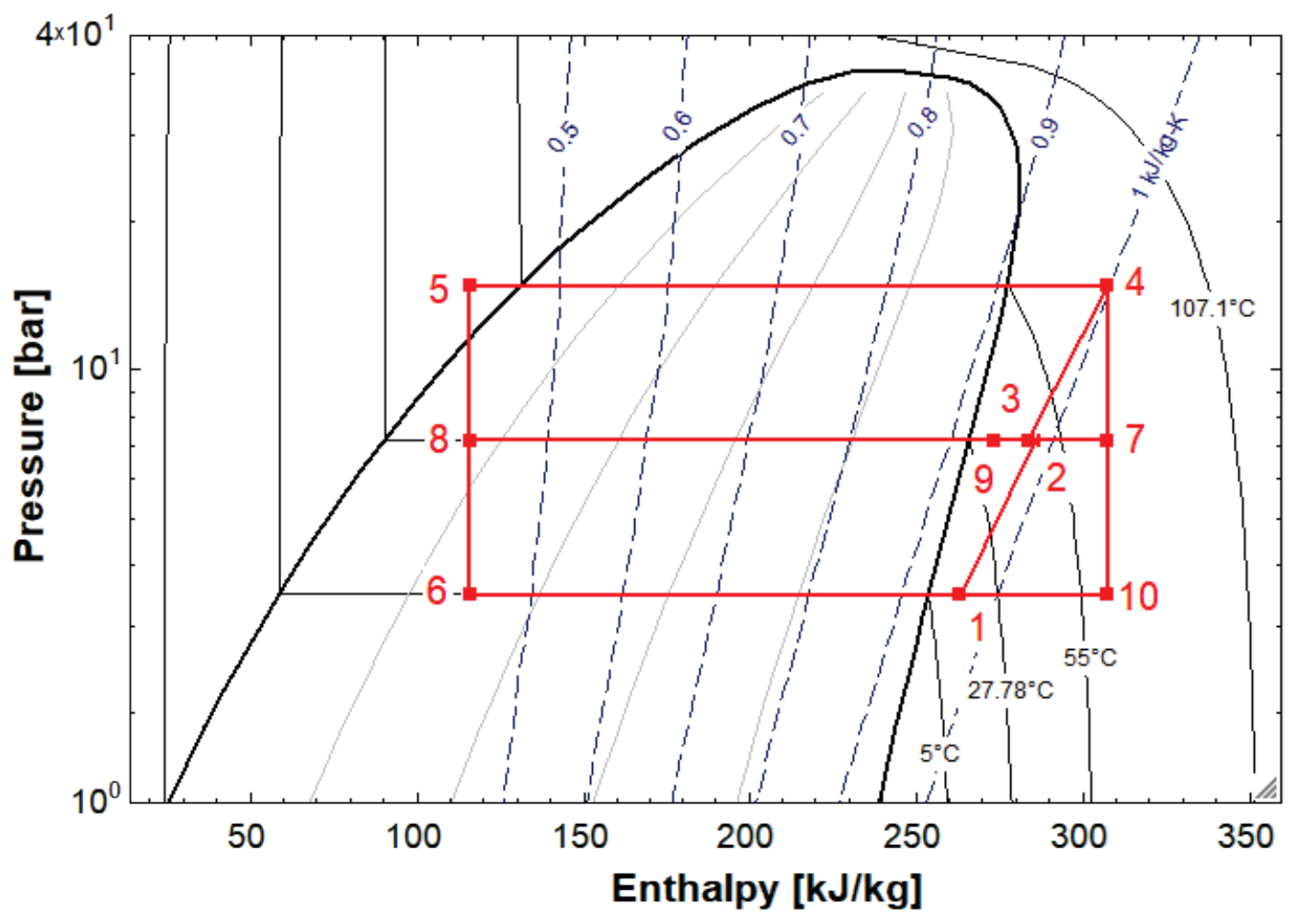

Figure 3: Pressure-enthalpy diagram of a hot-gas bypass system with economization

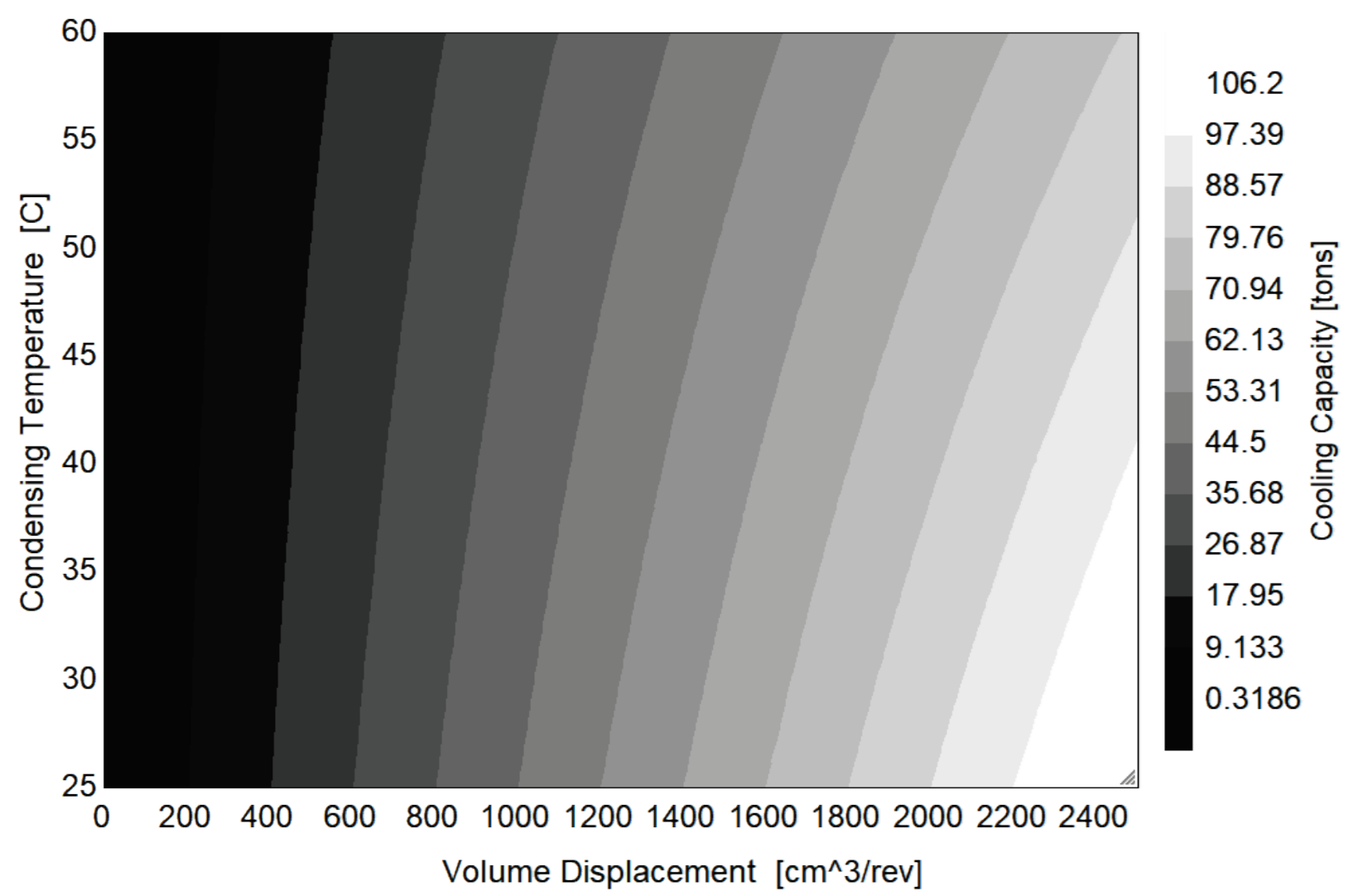

Figure 4: Cooling capacity for various condensing temperatures and volume displacements 


\subsection{Main Loop Circuit Design}

Due to the large operating range of the stand, careful consideration went into the design of the piping, most importantly, the sizing. Correct sizing ensures that recommended refrigerant velocities, oil entrainment up system risers, and appropriate mixing are achieved. Pipe size was determined using capacity tables specific to R134a found in the 2010 ASHRAE Refrigeration Handbook. Three separate circuits of varying sizes, each composed of a bypass, liquid, and suction line, provided the load stand with the versatility to use any configuration of these circuits. Where the bypass lines are defined as the hot-gas bypass plumbing downstream of the separation from the liquid line flow, but upstream of the mixing process. The liquid line is the same definition for the liquid line flow only, and the suction lines are the circuit sizes downstream of the mixing process.

The purpose of this analysis is to obtain acceptable refrigerant velocities when testing across the entire capacity range of compressors so that proper mixing and oil entrainment occurs where the separated mass flows converge in the main loop. This exercise was broken into three separate tasks to evaluate the pipe sizing for the hot-gas bypass lines, the suction lines (post-mixing), and the liquid lines of each of the three circuits. A series of decision matrices, seen in Tables 3-5, were developed using the model results to obtain the optimal combination of sizes for each circuit. The final selected case is shaded for each circuit.

The decision matrix contains proposed line sizes evaluated with one table for each circuit (bypass, suction, and liquid lines). Each table contains multiple cases consisting of a combination of three different pipe sizes. Conducting a parametric study in EES, the optimal combination of pipe sizes for each line could be determined by evaluating the refrigerant velocity in each proposed line at a range of operating conditions and capacities that represent the extremes the load stand expects to run. This study calculated refrigerant velocities over a range of compressor volume displacements (capacities) and condensing temperatures while holding other parameters such as evaporating temperature, subcooling, and superheat constant. The case that had the most velocities in the recommended range provided in the 2010 ASHRAE Refrigeration Handbook was selected for the final design. The main loop circuits in the form (bypass line size, liquid line size, suction line size) selected are (1-1/8", 1/2", 1-3/8"), (1-3/8", 7/8", 2-1/8"), and (2-1/8", 1-1/8", 3-5/8").

The bypass line table analyzed 12 different cases consisting of the proposed combinations of pipe sizes. Each case examined the two extreme condensing temperatures of $25^{\circ} \mathrm{C}$ and $60^{\circ} \mathrm{C}$ for a total of 280 velocities calculated, 140 velocities for each temperature. These velocities were then compared to the recommended range of 2000 to $3500 \mathrm{fpm}$, with the number of acceptable velocities presented in Table 3. To help further differentiate a best case, another 20 different velocity sets for each temperature, corresponding to a certain compressor volume displacement were evaluated with acceptable cases also presented in Table 3. This set total provided a more reliable metric for a circuit size decision because it expressed if any out of the seven circuit combinations worked for a certain volume displacement. From this analysis, the proposed combination with the most acceptable cases was the combination of $1-1 / 8$ ", 1-3/8", 2-1/8" pipe for the three hot-gas bypass circuits.

Table 3: Decision matrix for bypass line circuit combinations considered

\begin{tabular}{|l|l|l|l|l|l|l|l|l|l|l|l|l|}
\hline Case & 1 & 2 & 3 & 4 & 5 & 6 & 7 & 8 & 9 & 10 & 11 & 12 \\
\hline Bypass & $5 / 8$, & $5 / 8$, & $5 / 8$, & $5 / 8$, & $7 / 8$, & $7 / 8$, & $7 / 8$, & $7 / 8$, & $7 / 8$, & $1-1 / 8$, & $1-1 / 8$, & $1-1 / 8$, \\
Circuit & $1-3 / 8$, & $1-3 / 8$, & $1-5 / 8$, & $1-5 / 8$, & $1-3 / 8$, & $1-3 / 8$, & $1-3 / 8$, & $1-5 / 8$, & $1-5 / 8$, & $1-3 / 8$, & $1-3 / 8$, & $1-5 / 8$, \\
Size(in) & $2-5 / 8$ & $3-1 / 8$ & $2-5 / 8$ & $3-1 / 8$ & $2-1 / 8$ & $2-5 / 8$ & $3-1 / 8$ & $2-5 / 8$ & $3-1 / 8$ & $2-1 / 8$ & $2-5 / 8$ & $2-1 / 8$ \\
\hline Total/280 & 54 & 37 & 55 & 39 & 56 & 59 & 46 & 56 & 39 & 57 & 56 & 57 \\
\hline Set- & 24 & 19 & 25 & 20 & 33 & 31 & 31 & 29 & 24 & 36 & 33 & 33 \\
Total/40 & & & & & & & & & & & & \\
\hline
\end{tabular}

Table 4 presents the options considered for the suction line sizes. The suction line velocities are calculated for only one condensing temperature of $55^{\circ} \mathrm{C}$, and then compared to the recommended range of 900 to $4000 \mathrm{fpm}$, from the ASHRAE handbook. This analysis resulted in a final suction line combination of 1-3/8", 2-1/8", 3-5/8". 
Table 4: Decision matrix for suction line circuit combinations considered

\begin{tabular}{|l|l|l|l|l|l|l|l|l|}
\hline Case & 1 & 2 & 3 & 4 & 5 & 6 & 7 & 8 \\
\hline Suction & $1-1 / 8$, & $1-1 / 8$, & $1-1 / 8$, & $1-1 / 8$, & $1-3 / 8$, & $1-3 / 8$, & $1-3 / 8$, & $1-3 / 8$, \\
Circuit & $1-5 / 8$, & $1-5 / 8$, & $2-1 / 8$, & $2-1 / 8$, & $1-5 / 8$, & $1-5 / 8$, & $2-1 / 8$, & $2-1 / 8$, \\
Size(in) & $3-5 / 8$ & $4-1 / 8$ & $3-5 / 8$ & $4-1 / 8$ & $3-5 / 8$ & $4-1 / 8$ & $3-5 / 8$ & $4-1 / 8$ \\
\hline Total/140 & 72 & 66 & 77 & 71 & 74 & 68 & 79 & 72 \\
\hline
\end{tabular}

Table 5 presents the decision matrix for the two combinations considered for the liquid line. The liquid line table considered both $25^{\circ} \mathrm{C}$ and $60^{\circ} \mathrm{C}$ condensing temperatures, and compared the velocities to the recommended 300 fpm for liquid lines from the ASHRAE handbook. This results in a final liquid line combination of 1/2", 1-1/8", 1-3/8”.

Table 5: Decision matrix for liquid line circuit combinations considered

\begin{tabular}{|l|l|l|}
\hline Case & 1 & 2 \\
\hline Liquid & $1 / 2$, & $3 / 8$, \\
Circuit & $7 / 8$, & $3 / 4$, \\
Size(in) & $1-1 / 8$ & $7 / 8$ \\
\hline Total/280 & 265 & 244 \\
\hline
\end{tabular}

\subsection{Final Design Constraints}

An understanding of the limits of the load stand is essential in selecting the appropriate compressor to be tested. Future testing will require the use of multiple different refrigerants, and the knowledge of an appropriate compressor size and capacity is crucial to the safety and longevity of the load stand. Using the thermodynamic model and the constraint of operation at the design condition the operating capacity and maximum compressor displacement can be estimated. Table 4 shows some limits of possible refrigerants that will be tested.

Table 6: Predicted maximum capacity and accompanying compressor displacements that the load stand will support for $3550 \mathrm{rpm}$ operation at $55^{\circ} \mathrm{C}$ condensing

\begin{tabular}{|c|c|c|}
\hline Working Fluid & Max Capacity in Tons $(\mathrm{kW})$ & Max Volume Displacement $\left(\mathrm{cm}^{3}\right)$ \\
\hline R134a & $80(281)$ & 2200 \\
\hline R1234yf & $77(271)$ & 2265 \\
\hline R410A & $72(253)$ & 893 \\
\hline R32 & $74(260)$ & 827 \\
\hline R1234ze(E) & $61(215)$ & 2247 \\
\hline
\end{tabular}

\section{CONCLUSIONS AND FUTURE WORK}

A compressor load stand capable of testing a variety of compressors ranging at a wide range of capacities has been designed. The unique advantages to this design include its range of testing capacities from 10 to 80 tons, its ability to provide liquid or vapor injection through an economizer circuit, and its capability of oil control and injection. The range of capacities is the most advantageous aspect of the load stand, as it will allow for testing of compressors for several different applications. The economizer circuit gives the ability to test single or two stage compressors, which allows for even more testing variety. The ability to inject and control the oil in the system will add versatility to the system and will let the stand be able to operate at more conditions. The studies conducted on this load stand will focus on compressor efficiencies and how they are affected by changing parameters, mainly caused by the type of refrigerant used.

In the future, the load stand will be used to test compressors under new conditions specified by new refrigerants. LowGWP refrigerants such as R1234yf, R32, etc. will be tested on compressors for commercial and residential HVAC\&R systems. The experiments done with on the load stand will bring new information about compressor performance using new refrigerants and will allow their development to be accelerated in HVAC\&R systems, thereby reducing the environmental impact of compressors. 


\title{
NOMENCLATURE
}

Symbol
$\eta_{\text {vol }}$
$\eta_{i s}$
$\dot{m}$
$\rho$
$V_{d}$
$\omega$
$h$
$h_{s}$
$\dot{W}$
$u_{R}$
$R$

$x_{i}$
$u_{i}$

\author{
Description \\ Volumetric efficiency \\ Overall isentropic efficiency \\ Mass flow rate \\ Density \\ Compressor displacement volume \\ Rotational speed of compressor \\ Specific enthalpy \\ Isentropic specific enthalpy \\ Power output of compressor \\ Relative uncertainty in $\mathrm{R}$ \\ Dependent variable of uncertainty \\ equation \\ Variables affecting $\mathrm{R}$ \\ Uncertainty in $x_{i}$
}

Units

--
--
$\mathrm{kg} / \mathrm{s}$

$\mathrm{kg} / \mathrm{m}^{3}$

$\mathrm{m}^{3}$

$\mathrm{rev} / \mathrm{s}$

$\mathrm{kJ} / \mathrm{kg}$

$\mathrm{kJ} / \mathrm{kg}$

$\mathrm{kW}$

$--$

\section{REFERENCES}

ASHRAE. (2010). Methods of Testing for Rating the Performance of Positive Displacement Refrigerant Compressors and Condensing Units that Operate at Subcritical Temperatures of the Refrigerant (ASHRAE 23.1-2010). Atlanta, GA: American Society of Heating, Refrigerating, and Air-Conditioning Engineers, Inc.

ASHRAE Handbook. (2010). ASHRAE Handbook-Refrigeration. Atlanta, GA: American Society of Heating, Refrigerating, and Air-Conditioning Engineers, Inc.

Bell, I. H. (2011). Theoretical and experimental analysis of liquid flooded compression in scroll compressors (Doctoral dissertation, Purdue University, 2011). Ann Arbor, MI: Proquest.

Bradshaw, C. R., Groll, E. A., Garimella, S.V., (2011). A comprehensive model of a miniature-scale linear compressor for electronics cooling. International Journal of Refrigeration 34, 63-73.

Bradshaw, C. R., \& Groll, E. A. (2013). A comprehensive model of a novel rotating spool compressor. International Journal of Refrigeration, 36(7), 1974-1981.

Bradshaw, C. R. (2014, July 13). Compressor Performance Measurements Using Hot-Gas Bypass Load Stands. Lecture presented at Short Course on Experimental Techniques to Measure Compressor Performance and Reliability in Purdue University, West Lafayette, IN.

Doniger, D. (2016, December 15). Countries Adopt Kigali Amendment to Phase Down HFCs. From https://www.nrdc.org/experts/david-doniger/countries-adopt-kigali-amendment-phase-down-hfcs

Gu, R., \& Mathison, M. M. (2014). Design of a Compressor Load Stand Capable of Supplying Two-Phase Refrigerant at Two Intermediate Pressures. International Compressor Engineering Conference

Orosz, J., Bradshaw, C. R., Kemp, G., \& Groll, E. A. (2014). An update on the Performance and Operating Characteristics of a Novel Rotating Spool Compressor. International Compressor Engineering Conference.

Orosz, J., Bradshaw, C. R., Kemp, G., \& Groll, E. A. (2016). Updated Performance and Operating Characteristics of a Novel Rotating Spool Compressor. International Compressor Engineering Conference.

Sathe, A., Groll, E. A., \& Garimella, S. (2008). Experimental Evaluation of a Miniature Rotary Compressor for Application in Electronics Cooling. International Compressor Engineering Conference.

U.S. Energy Information Administration. (2018, April 26). Monthly Energy Review(Rep. No. April 2018). Retrieved May 29, 2018, from U.S. Department of Energy website: https://www.eia.gov/totalenergy/data/monthly/archive/00351804.pdf 